\title{
Diagnostic and Prognostic Value of Plasma Gelsolin in Multiorgan Failure in Patients with Sepsis
}

\author{
Ahmed El-Maghraby ${ }^{1 *}$, Hossam Mowafy², Emad Omer ${ }^{2}$, Hazem El-Akabawy², Iris Nessim³ \\ ${ }^{1}$ Department of Critical Care Medicine, Theodor Bilharz Research Institute, Cairo, Egypt; ${ }^{2}$ Department of Critical Care Medicine, \\ Cairo University, Cairo, Egypt; ${ }^{3}$ Clinical Chemistry Unit, Theodor Bilharz Research Institute, Cairo, Egypt
}

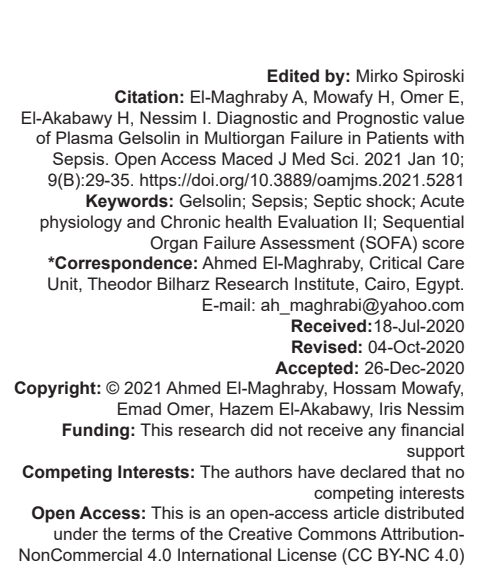

\section{Introduction}

Sepsis is among the most common reason for admission to intensive care units (ICU's) throughout the world. An epidemiologic study in European ICU's demonstrated an incidence of $37 \%$ for sepsis and $30 \%$ for severe sepsis [1]. While the exact incidence of sepsis in the US is unclear (300-1000 cases/100,000 population per year) the annualized incidence has been reported to have increased by between $8.7 \%$ and $13 \%$ over the last 30 years. The aging of the population is believed to be largely responsible for the increasing incidence of sepsis in developed counties [2].

Epidemiological data from 2004 to 2009 demonstrated a decrease in in-hospital mortality from $35 \%$ to $26 \%$. This study estimated that there were 229,044 deaths from severe sepsis in 2009 , which would place severe sepsis as the third most common cause of death, after heart disease and malignant neoplasm. The 1-year all-cause mortality of patients treated for severe sepsis and septic shock may be as high as 44\% [3].

In addition, recent data suggests that patients who have had a septic episode are at an increased risk of death for up to 5 years following the acute event [4], [5].

Among promising novel biomarkers is plasma Gelsolin (pGSN), which is an actin-binding plasma protein that is part of an "actin-scavenging" system that buffers potentially harmful actin molecules released from injured tissues. GSN is a calcium-dependent actin-binding protein that severs actin filaments and caps their fast-growing "barbed" ends. An isoform normally present in plasma may serve to fragment actin filaments leaking out of damaged cells and block further elongation of their barbed ends [6], [7]. After binding actin, these complexes are cleared from the circulation, thereby protecting the host from further injury [8], [9]. The pathophysiological role of actin, leaked from damaged cells, as a major contributor to the propagation of organ injury after an initial insult is under increasing scrutiny [10]. Actin is the principal component of the microfilaments that form the cytoskeleton of all motile and phagocytic eukaryotic cells. It is the most abundant protein in the cytosol of these cells, constituting $>10 \%$ of the total protein. When cells are lysed in vivo by any pathological process, cytoplasmic actin is released into an extracellular milieu that is favorable for the 
polymerization of actin [11]. Filamentous actin may then cause secondary injury to already damaged organs by occluding the microvascular circulation and by activating platelets and the clotting cascade [12]. There has been accumulated evidence that decreases in a circulating actin-binding protein, pGSN to critical levels precede and therefore predict complications [13], [14].

In humans, extensive tissue injury in trauma, acute respiratory distress syndrome, hematopoietic stem cell transplantation, acute hepatic failure, and myonecrosis lead to pGSN decrements, and in critically ill surgical patients, very low pGSN levels predict poor outcomes. Low circulating levels of pGSN may indicate significant depletion of this actin-scavenger system and may serve as a marker of injury severity in critically ill patients [15], [16]. Little is known about the course of pGSN levels over time in patients with severe sepsis.

The aim of this work is to define the role of pGSN as a valid marker for early detection of multiorgan failure in sepsis and septic shock patients.

\section{Patients and Methods}

\section{Patients}

Eighty patients who had been diagnosed with sepsis according to ACCP/SCCM criteria [17] admitted to the Critical Care Department at Cairo University Hospital and the Intensive Care Unit at Theodor Bilharz Research Institute, Egypt, from October 2015 to September 2016 were enrolled in this prospective observational multicenter study. The study was approved by the institution review board at Cairo University. This study did not interfere with normal routine patient management. Informed consent given by the patient or immediate relative (first degree) ACCP/ SCCM criteria include: (1) Clinically suspected infection as per the treating physician or confirmed infection and (2) 2 or more of the following: Temperature $>38^{\circ} \mathrm{C}$ $\left(100.4^{\circ} \mathrm{F}\right)$ or $<36^{\circ} \mathrm{C}\left(96.8^{\circ} \mathrm{F}\right)$, heart rate $(\mathrm{HR})>90 / \mathrm{min}$, respiratory rate $(\mathrm{RR})>20 / \mathrm{min}$ or $\mathrm{PaCO}_{2}<32 \mathrm{mmHg}$, and white blood cell count $>12,000 / \mathrm{mm}^{3}$ or $<4000 / \mathrm{mm}^{3}$ or $>$ $10 \%$ immature neutrophils. Severe sepsis is defined as sepsis plus sepsis-induced organ dysfunction or tissue hypoperfusion. Septic shock is defined as sepsisinduced hypotension persisting despite adequate fluid resuscitation. Sepsis-induced hypotension is defined as a systolic blood pressure (BP) $<90 \mathrm{mmHg}$ or mean arterial pressure (MAP) $<70 \mathrm{mmHg}$ or a systolic BP decrease $>40 \mathrm{mmHg}$ in the absence of other causes of hypotension.

${ }^{* *}$ Exclusion criteria included patients $<18$ years, trauma, burns, post-operative patients, and patients with a history of chronic liver disease, malignancy, or on chronic hemodialysis.
Patients were included into the study on the day of ICU admission, and subsequently followed up until the day of hospital discharge or demise.

The blood samples were also collected from 40 consecutive non-specific age- and sex-matched subjects as a control. Patients were followed during ICU stay and only patients who did not develop infection were enrolled. This group included patients admitted with acute coronary syndrome, heart failure, arrhythmias, acute pulmonary edema, obstetric emergencies (eclampsia), patients with cerebrovascular accident, epilepsy, pulmonary embolism, and others.

\section{Evaluation of patients} following:

All included patients were subjected to the

\section{Full clinical evaluation}

Including a history and physical examination with a special emphasis on vital signs (BP, HR, temperature, and RR) and GCS; these were evaluated on the day of admission and then followed up daily (every $2 \mathrm{~h}$ for vital signs and once daily for GCS).

\section{Imaging investigations}

Chest X-ray, computed tomography brain, or abdominal sonography were done when needed.

\section{Laboratory investigations}

\section{Routine Labs}

Complete blood count, kidney function tests: $\mathrm{Na}, \mathrm{K}$, serum creatinine, and blood. Urea; liver function tests: Alanine aminotransferase, aspartate aminotransferase, total bilirubin, and albumin; and arterial blood gas. These routine labs were withdrawn on study day 1 and subsequently thereafter every day until ICU discharge or demise.

\section{Microbiological studies}

Pancultures were sent including sputum, blood, urine and biological fluids. Cultures were sent before antibiotic administration or 48 hours after discontinuation of antibiotics.

\section{Specific labs for this study}

pGSN [18] was measured using a doubleantibody sandwich enzyme-linked immune sorbent assay on the day of admission thereafter every day for 5 days. Collected heparinated blood sample was centrifuged within $1 \mathrm{~h}$ and stored at $-70^{\circ} \mathrm{C}$. Then, samples were 
added to the appropriate microtiter plate wells pre-coated with the specific biotin-conjugated polyclonal antibody enzyme specific for GSN. Next, avidin conjugated to horseradish peroxidase is added to each microplate well and incubated. Then, a 3,3',5,5'-tetramethylbenzidine (TMB) substrate solution is added to each well. Only those wells that contain GSN, biotin-conjugated antibody, and enzyme-conjugated Avidin will exhibit a change in color. The enzyme-substrate reaction is terminated by the addition of a stop solution (sulfuric acid solution) and the color change is measured spectrophotometrically at a wavelength of $450 \mathrm{~nm}$. The concentration of the GSN in the samples is then determined by comparing the O.D. of the samples to the standard curve. This assay has high sensitivity and excellent specificity for detection of GSN.

\section{Clinical data}

Length of ICU stays; multiorgan dysfunction and need for organ supportive measures (vasopressors, mechanical ventilation, and/or hemodialysis) were reported for all patients until ICU discharge or demise.

\section{Scoring systems}

Acute physiology and chronic health evaluation II (APACHE II) score [19] which is a severity of disease classification system was evaluated on the day of admission. After admission, an integer score is computed based on several measurements; higher scores imply a more severe disease and a higher risk of death. Sepsis-related Organ Failure Assessment (SOFA) score [20] was evaluated on study day 1 and serially every day until ICU discharge or demise. This score determines the extent of a person's organ function or rate of failure.

\section{Statistics}

Continuous variables were summarized using range and mean and SD. Categorical variables were summarized using frequencies and relative frequencies. Continuous variables were compared using nonparametric Mann-Whitney $U$ test for those which are not normally distributed. Categorical variables were compared using the Chi-square and exact test was used when the expected frequency was <5. Receiver operator characteristic (ROC) analysis was used to determine the optimum cutoff value for the studied diagnostic markers. Correlation between various variables was done using Person correlation equation for non-normal variables. A probability value $(p<0.05)$ was considered statistically significant. All statistical calculations were done using (Statistical Package for the Social Science; SPSS Inc., Chicago, IL, USA) version 22 for Microsoft Windows.

\section{Results}

The mean ICU admission pGSN level for the septic patients was significantly lower than that in control subjects $(169.5+74.4$ [42-320] vs. $227.3+84.7$ [85-390], $p=0.010)$. There was a significant change from admission pGSN to $2^{\text {nd }}$ day pGSN $(169.5+74.4$ vs. $157.3+72.2, p \leq 0.001)$ and from $3^{\text {rd }}$ day $p G S N$ to $4^{\text {th }}$ day pGSN $(152.9+66.7$ vs. $148.8+58.9, p=0.013)$. However, there were no significant changes from $2^{\text {nd }}$ day pGSN to $3^{\text {rd }}$ day pGSN $(p=0.623)$ and from $4^{\text {th }}$ day $p G S N$ to $5^{\text {th }}$ day pGSN ( $\left.p=0.582\right)$. Moreover, the levels of pGSN in the studied septic patients decreased with the increasing severity of the septic condition at ICU admission (Table 1).

Table 1: Distribution of pGSN levels with organ dysfunction and mortality in the patients of the study

\begin{tabular}{|c|c|c|c|}
\hline \multirow[t]{2}{*}{ Ventilatory support } & No & Yes & \multirow[t]{2}{*}{$p$-value } \\
\hline & Mean \pm SD & Mean \pm SD & \\
\hline pGSN ( $1^{\text {st }}$ day $)$ & $204.9 \pm 76.6$ & $141.4 \pm 77.6$ & 0.005 \\
\hline ( $2^{\text {nd }}$ day $)$ & $174.4 \pm 70.7$ & $134.5 \pm 69.8$ & 0.074 \\
\hline ( $3^{\text {rd }}$ day) & $171.0 \pm 60.8$ & $131.9 \pm 68.9$ & 0.079 \\
\hline ( $4^{\text {th }}$ day) & $168.8 \pm 47.8$ & $125.9 \pm 64.6$ & 0.041 \\
\hline ( $5^{\text {th }}$ day $)$ & $159.4 \pm 60.4$ & $123.7 \pm 65.5$ & 0.143 \\
\hline RRT & No & Yes & \\
\hline pGSN (1 $1^{\text {st }}$ day $)$ & $202.7 \pm 78.9$ & $130.6 \pm 64.4$ & 0.003 \\
\hline ( $2^{\text {nd }}$ day) & $180.1 \pm 62.9$ & $109.4 \pm 69.8$ & 0.002 \\
\hline ( $3^{\text {rd }}$ day) & $175.4 \pm 64.5$ & $116.1 \pm 56.2$ & 0.012 \\
\hline ( $4^{\text {th }}$ day) & $163.5 \pm 56.8$ & $125.7 \pm 56.2$ & 0.057 \\
\hline ( $5^{\text {th }}$ day $)$ & $162.3 \pm 65.8$ & $123.6 \pm 60.7$ & 0.293 \\
\hline Circulatory failure & No & Yes & $p$-value \\
\hline pGSN ( $\left({ }^{\text {st day }}\right)$ & $211.8 \pm 75.8$ & $128.4 \pm 13.9$ & $<0.001$ \\
\hline ( $2^{\text {nd }}$ day $)$ & $199.6 \pm 59.9$ & $122.5 \pm 68.5$ & $<0.001$ \\
\hline ( $3^{\text {rd d }}$ day) & $188.9 \pm 65.1$ & $119.8 \pm 56.3$ & 0.002 \\
\hline ( $4^{\text {th }}$ day) & $178.3 \pm 52.7$ & $125.4 \pm 55.3$ & 0.013 \\
\hline ( $5^{\text {th }}$ day $)$ & $170.5 \pm 52.0$ & $122.5 \pm 65.7$ & 0.042 \\
\hline Mortality & No & Yes & $p$-value \\
\hline pGSN (1 $1^{\text {st }}$ day $)$ & $197.6 \pm 73.8$ & $124.2 \pm 57.3$ & 0.005 \\
\hline ( $2^{\text {nd }}$ day $)$ & $177.1 \pm 72.5$ & $114.4 \pm 50.7$ & 0.008 \\
\hline ( $3^{\text {rd }}$ day) & $173.4 \pm 65.7$ & $108.1 \pm 44.2$ & 0.004 \\
\hline ( $4^{\text {th }}$ day) & $167.9 \pm 55.9$ & $105.3 \pm 46.2$ & 0.006 \\
\hline ( $5^{\text {th }}$ day $)$ & $163.3 \pm 61.6$ & $96.4 \pm 44.2$ & 0.007 \\
\hline
\end{tabular}

The mean pGSN levels were significantly higher in patients who required MV (39 patients), required vasopressors support (52 patients), and required hemodialysis (28 patients) than those who did not require them $(41,28$, and 52 patients, respectively).

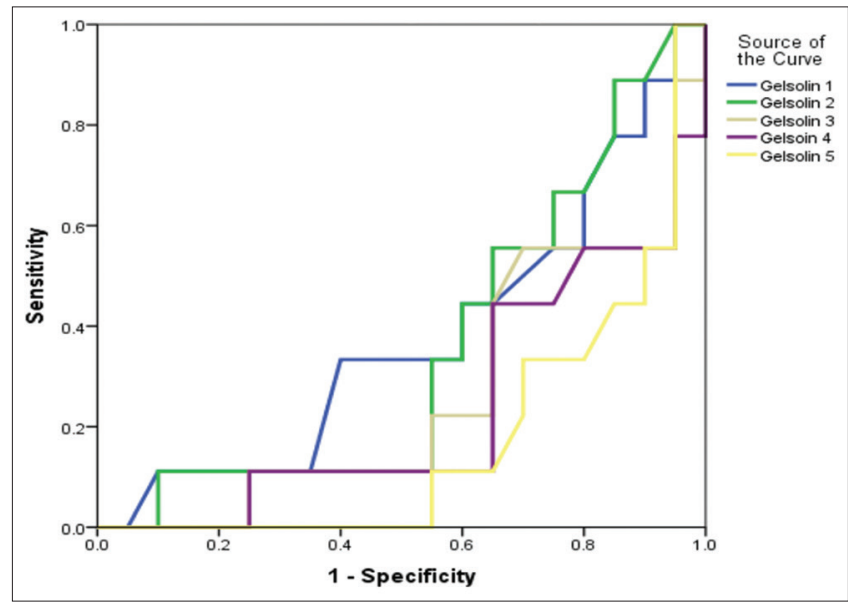

Figure 1: Receiver operator characteristic curve analysis of plasma gelsolin (GSN) levels for prediction of mortality. ${ }^{* * *}$ Prognostic ability of GSN 
ROC curve was calculated for GSN as a predictor of ICU mortality. The area under the ROC curve to predict ICU mortality was $37.8 \%$. The optimal cutoff value to predict ICU mortality was 129 . This cutoff value gave a sensitivity of $44.4 \%$ and a specificity of 40\% (Figure 1).

\section{Discussion}

Sepsis is one of the main causes of morbidity and mortality in the intensive care unit. The challenges of diagnosing and treating sepsis only seem more daunting as incidence increases, patients become older and sicker, and pathogenic organisms evolve [21], [22]. Evidence supports early intervention [23] and diagnosis in sepsis and that the failure to intervene results in significant morbidity and mortality [24].

These complexities have led to the search for the "troponin" of sepsis, a biomarker or set of biomarkers with compelling sensitivity and specificity for effectively identifying the disease, patients at risk for untoward outcomes, and reliably guiding treatment. Hence, the aim of the present study was to investigate pGSN as biomarker for sepsis in regard to its diagnostic and prognostic value.

Both septic and non-septic included patients were comparable with no significant differences as regard their demographic, clinical data, and co-morbidities, except baseline temperature which was significantly higher in sepsis group and MAP which was significantly lower in sepsis group. This was in agreement with study by Giuliano et al. [25] and Liu et al. [26] who found that the presence of an elevated temperature was associated with the highest risk of sepsis. Shapiro et al. [27], however, concluded that this was not pathognomonic to sepsis and may also be observed in a wide variety of non-infectious inflammatory conditions.

Our study also revealed that there was significant difference between septic and non-septic patients for their neurologic impairment (GCS), need for mechanical ventilator, and renal replacement therapy. This was also shown by Wilson et al. [28] who proved that advanced sepsis can cause brain damage and that milder cases may recover without neurological problem. These cases may be related to the reversible mechanisms of what is called Sepsis-associated encephalopathy. However, more advanced cases of sepsis may have neuron-killing complications.

There was statistically significant difference in the incidence of mechanical ventilation, need for renal replacement therapy, and vasoactive support in sepsis and control groups in our study. Lagu et al. [29] also reported that non-septic patients were less likely to receive a code for respiratory failure than patients with sepsis or to receive a code for shock or other cardiovascular failure.

In our study, length of ICU and hospital stay was significantly higher in septic than non-septic patients. This was consistent with Melville et al. [30] concluded that patients with sepsis needed longer ICU care, with the average length of stay almost doubled.

In our model, we enrolled APACHE II score with SOFA score which are known as landmarks in critical care practice in predicting survival and disease severity.

Our study showed significant changes among daily SOFA scores in survivors versus nonsurvivors where SOFA scores showed a pattern of daily decremental changes in survivors and another pattern of non-decremental changes in non-survivors. These two patterns differed significantly. ROC analysis could present cutoffs for daily SOFA scores to predict mortality. The best discriminating SOFA scores were at day 1 and day 2 .

Ferreira also studied serial evaluation of SOFA scores to predict outcome in critically ill patients and he concluded that the initial, highest, and mean SOFA scores correlated well with mortality. Except for initial scores of more than 11 (mortality rate $>90 \%$ ), a decreasing score during the first $48 \mathrm{~h}$ was associated with a mortality rate of $<6 \%$, while an unchanged or increasing score was associated with a mortality rate of $37 \%$ when the initial score was $2-7$ and $60 \%$ when the initial score was 8-11. Independent of the initial score, an increase in SOFA score during the first $48 \mathrm{~h}$ in the ICU predicts a mortality rate of at least $50 \%$ [31].

We reported a higher degree of disease severity and organ failure in sepsis group as indicated by significantly higher SOFA and APACHE II scores in septic patients, also, patient with severe sepsis and septic shock has higher scores. Liu et al. [32] showed no difference in APACHE II score between sepsis and no sepsis group; however, it was significantly higher in severe sepsis and septic shock than in sepsis. Yousef and Suliman [33] showed higher SOFA score in sepsis patients.

Daviaud et al. investigated causes of death in septic shock of 543 patients and concluded that higher admission SOFA score remained an independent risk factor of early death, which was defined within the first 3 days of ICU admission [34].

GSN is a calcium dependent actin binding protein predominantly responsible in removal of actin filaments released into circulation upon cell injury [10]. Diminished levels of GSN were observed in human subjects affected with acute liver injury, myocardial infarction, sepsis, and myonecrosis in comparison to the healthy people. The study showed that the prognosis of the disease depends on the extent of reduction in pGSN values [35]. 
The present study revealed that pGSN levels measured at the time of ICU admission in patients with sepsis were lower than those in non-septic critically ill patients, also were lower in patients with septic shock than in patients with severe sepsis and sepsis. Septic patients showed lower GSN level $170.9 \pm 74.3 \mathrm{mg} / \mathrm{l}$. Peak GSN was at day 1. Controls showed GSN level $225.9 \pm 84.5 \mathrm{mg} / \mathrm{l}$ on admission.

Although plasma albumin levels in both severe septic group and non-septic critically ill group were below the normal value, there was no significant difference between the two groups. This indicates that the decrease in pGSN level was specific and not a simple consequence of systemic plasma protein loss or dilution.

Lee et al. examined the role of pGSN also in animal models of sepsis. He documented the depletion of pGSN (25-50\% of normal) in murine models of sepsis, associated with the presence of circulating actin within $6 \mathrm{~h}$ of septic challenge. Repletion of pGSN led to solubilization of circulating actin aggregates and significantly reduced mortality in endotoxemic mice (survival rates were $88 \%$ in the GSN group vs. $0 \%$ in the saline group, $p<0.001$ ) and in CLP-challenged mice (survival rates were $30 \%$ in the GSN group vs. $0 \%$ in the saline group, $p=0.001$ ) [36].

In another study, Lee et al. also studied pGSN depletion and circulating actin in sepsis. He concluded that circulating actin and pGSN deficiency are associated with early sepsis. The degree of pGSN deficiency correlated with sepsis mortality. He proposed that reversing pGSN deficiency may be an effective treatment for sepsis [37].

In search for therapeutic potentials of GSN in sepsis, Cohen et al. hypothesized that repletion of GSN would limit inflammation and tissue injury in a rat model of sepsis, using cecal ligation and double puncture. He stated that exogenous GSN could reduce morbidity from sepsis [38].

Wang et al. examined levels of pGSN in patients with severe sepsis. The admission GSN levels were significantly decreased in severe sepsis (20.6 \pm $11.7 \mathrm{mg} / \mathrm{l}$ ) compared with non-septic critically ill patients (52.3 $\pm 20.3 \mathrm{mg} / \mathrm{l} ; \mathrm{p}<0.001)$ and healthy control individuals $(126.8 \pm 32.0 \mathrm{mg} / \mathrm{l} ; \mathrm{p}<0.001)$. Survivors of severe sepsis exhibited substantial recovery of their depressed pGSN levels, whereas GSN levels in nonsurvivors remained at or below their depleted admission levels [39].

In our study, we observed that almost all the patients with sepsis had decreased GSN level, the lowest levels were associated with highest SOFA score and more complicated disease courses.

We also found that the pGSN levels were lower in patients with multiple organ dysfunction syndrome (MODS) (need for ventilator support, renal replacement therapy and vasopressors) than those without MODS and healthy control individuals. Moreover, as the pGSN levels decreased, the incidences of septic complication as well as MODS remarkably increased. It seemed that the pGSN level might correlate with occurrence of severe sepsis and MODS and it did significantly differ between surviving and non-surviving patients with MODS.

Huang et al. also studied the prognostic implications of GSN levels on the development of MODS and fatal outcome in a group of severely burn patients. The results showed that GSN concentrations decreased markedly. Moreover, as the GSN levels decreased, the incidence of septic complication as well as MODS remarkably increased [40].

Despite that there were significant changes daily patterns of pGSN measurements among survivors and non-survivors but diminished pGSN levels had a week ability to predict mortality in our study. The area under the ROC curve to predict ICU mortality was $37.8 \%$. The optimal cutoff value to predict ICU mortality was 129 . This cutoff value gave a sensitivity of $44.4 \%$ and a specificity of $40 \%$.

Mounzer et al. demonstrated that low pGSN levels at admission were associated with increased risk for adverse outcomes, including prolonged length of hospital stay and death, in patients who had undergone surgery or who had suffered trauma [15].

Lee et al. examined pGSN measurements in critically ill patient and concluded that low pGSN levels were associated with increased risk of death occurring in the ICU. pGSN levels lower than $61 \mathrm{mg} / \mathrm{L}$ predicted longer ICU stay, prolonged ventilator dependence, and increased overall in-hospital mortality [14].

Interestingly, Lee et al. studied pGSN level in chronic hemodialysis patients and noted that low pGSN and detectable circulating actin identify chronic hemodialysis patients at highest risk for 1-year mortality [41]

Furthermore, DiNubile et al. examined pGSN levels in patients with allogeneic stem cell transplantation and suggested that GSN levels shortly after allogeneic HSCT can predict the later development of fatal IPS [16].

To the best of our knowledge, there are no studies assessing the predictive ability for pGSN in mortality from sepsis. However, late in 2016, Szalai et al. [21] studied the predictive value of serum actin, GSN, and the recently defined actin/GSN ratio during sepsis by comparison it to classical clinical and inflammatory laboratory parameters. The study was done on 46 cases of severe septic $(n=32)$ and SIRS $(n=12)$ patients for 5 days. Ophthalmologic patients $(n=27)$ served as controls. In concordance with our results, the study found that septic patients showed significantly decreased $1^{\text {st }}$-day GSN levels and increased actin/GSN ratios compared to non-septic patients; furthermore, non-survivors had significantly lower GSN levels compared to survivors. 


\section{The limitations of the study were as}

\section{follows}

The number of patients with sepsis enrolled in the time course study is inadequate to allow definitive conclusions to be drawn, and the study does not elucidate the role played by $\mathrm{pGSN}$ in sepsis or the association of pGSN with actin and cytokines.

\section{Conclusion}

pGSN may be a valuable marker for sepsis. pGSN could direct our efforts in rescuing those risky populations and could be part of our ammunition for fighting sepsis. There was strong statistically significant negative correlation between pGSN and both APACHE II and SOFA scores. Sepsis could result in significantly decreased pGSN levels, which appears to be associated with the development of MODS and fatal outcome secondary to acute insults. However, GSN measurements could not predict mortality with much accuracy compared to other studied parameters. Given the incredible complexity and variability of the disease, host, and pathogen, biomarker panels or composite markers may prove most useful in examining a particular immunologic pathway, predicting organ specific response, and, ideally, identifying at-risk individuals who require aggressive intervention and monitoring.

\section{References}

1. Vincent JL, Sakr Y, Sprung CL, Ranieri VM, Reinhart K, Gerlach $\mathrm{H}$, et al. Sepsis in European intensive care units: Results of the SOAP study. Crit Care Med. 2006;34(2):344-53. https://doi.org/10.1097/01.ccm.0000194725.48928.3a PMid:16424713

2. Martin GS, Mannino DM, Moss M. The effect of age on the development and outcome of adult sepsis. Crit Care Med. 2006;34(1):15-21.

PMid:16374151

3. Opal SM, Laterre PF, Francois B, LaRosa SP, Angus DC, Mira JP, et al. Effect of eritoran, an antagonist of MD2-TLR4, on mortality in patients with severe sepsis: The ACCESS randomized trial. JAMA. 2013;309(11):1154-62. https://doi.org/ 10.3410/f.717991612.793473478

\section{PMid:23512062}

4. Wang HE, Szychowski JM, Griffin R, Safford MM, Shapiro NI, Howard G. Long term mortality after sepsis. Chest. 2013;21(12):E762-9.

5. Winters BD, Eberlein M, Leung J, Needham DM, Pronovost PJ, Sevransky JE. Long-term mortality and quality of life in sepsis: A systematic review. Crit Care Med. 2010;38(5):1276-83. PMid:20308885

6. Janmey PA, Lind SE. Capacity of human serum to depolymerize actin filaments. Blood. 1987;70(2):524-30. https://doi. org/10.1182/blood.v70.2.524. bloodjournal702524

PMid:3038216

7. Kwiatkowski DJ, Mehl R, Izumo S, Nadal-Ginard B, Yin HL. Muscle is the major source of plasma gelsolin. J Biol Chern 1988;263(17):8239-43.

PMid:2836420

8. Lind SE, Smith DB, Janmey PA, Stossel TP. Role of plasma gelsolin and the Vitamin D-binding protein in clearing actin from the circulation. J Clin Invest. 1986;78(3):736-42.

PMid:3018044

9. Goldschmidt-Clermont PJ, Van Baelen H, Bouillon R, Shook TE, Williams $\mathrm{MH}$, Nel AE. Role of group specific component (vitamin $\mathrm{D}$ binding protein) in clearance of actin from the circulation in the rabbit. J Clin Invest. 1988;81(5):1519-27. https://doi.org/10.1172/jci113484 PMid:3366905

10. Lee WM, Galbraith RM. The extracellular actin-scavenger system and actin toxicity. N Engl J Med. 1992;326(20):1335-41. https://doi.org/10.1056/nejm199205143262006

PMid:1314333

11. Lee WM, Reines D, Watt GN, Cook JA, Wise WC, Halushka PV et al. Alterations in Gc protein levels and complexing in septic shock. Circ Shock. 1989;28(3):249-55.

PMid:2766479

12. Smith DB, Janmey PA, Lind SE. Circulating actin-gelsolin complexes following oleic acid-induced lung injury. Am J Pathol. 1988;130(2):261-7.

PMid:2829631

13. DahIB, SchiodtFV, OttP, Gvozdenovic R, Yin HL, LeeWM.Plasma gelsolin is reduced in trauma patients. Shock. 1999;12(2):102-4. https://doi.org/10.1097/00024382-199908000-00002 PMid:10446889

14. Lee PS, Drager LR, Stossel TP, Moore FD, Rogers SO Relationship of plasma gelsolin levels to outcomes in critically ill surgical patients. Ann Surg. 2006;243(3):399-403. https://doi. org/10.1097/01.sla.0000201798.77133.55 PMid:16495706

15. Mounzer KC, Moncure M, Smith YR, Dinubile MJ. Relationship of admission plasma gelsolin levels to clinical outcomes in patients after major trauma. Am J Respir Crit Care Med. 1999;160(5 Pt):1673-81. https://doi.org/10.1164/ajrccm.160.5.9807137 PMid:10556139

16. DiNubile MJ, Stossel TP, Ljunghusen OC, Ferrara JL, Antin JH Prognostic implications of declining plasma gelsolin levels after allogeneic stem cell transplantation. Blood. 2002;100(13):436771. https://doi.org/10.1182/blood-2002-06-1672

PMid:12393536

17. Levy MM, Fink MP, Marshall JC, Abraham E, Angus D, Cook D et al. 2001 SCCM/ESICM/ACCP/ATS/SIS international sepsis definitions conference. Crit Care Med. 2003;31(4):1250-6. https://doi.org/10.1007/s00134-003-1662-x PMid:12682500

18. Horváth-Szalai Z, Kustán $P$, Mühl D, Ludány $A$, Bugyi $B$, Kőszegi T. Antagonistic sepsis markers: Serum gelsolin and actin/gelsolin ratio. The Canadian society of clinical chemists. Clin Biochem J 2017;50(3):127-33. https://doi.org/10.1016/j. clinbiochem.2016.10.018 PMid:27823961

19. Knaus WA, Draper EA, Wagner DP, Zimmerman JE APACHE II: A severity of disease classification system. Crit Care Med 1985;13:818-29. https://doi. org/10.1097/00003246-198510000-00009

PMid:3928249 
20. Vincent JL, Moreno R, Takala J, Willatts S, De Mendonça A, Bruining $\mathrm{H}$, et al. The SOFA (Sepsis-related Organ Failure Assessment) score to describe organ dysfunction/failure. On behalf of the working group on sepsis-related problems of the European society of intensive care medicine. Intensive Care Med. 1996;22(7):707-10. https://doi.org/10.1007/ bf01709751

\section{PMid:8844239}

21. Martin GS, Mannino DM, Eaton S, Moss M. The epidemiology of sepsis in the United States from 1979 through 2000. N Engl J Med. 2003;348(16):1546-54.

\section{PMid: 12700374}

22. Annane D, Aegerter P, Jars-Guincestre MC, Guidet B; CUB-Réa Network. Current epidemiology of septic shock: The CUBRea Network. Am J Respir Crit Care Med. 2003;168(2):165-72. https://doi.org/10.1164/rccm.2201087

PMid:12851245

23. Rivers E, Nguyen B, Havstad S, Ressler J, Muzzin A, Knoblich B, et al. Early goal-directed therapy in the treatment of severe sepsis and septic shock. N Engl J Med. 2001;345(19):1368-77. https://doi.org/10.1056/nejmoa010307 PMid:11794169

24. Levy MM, Macias WL, Vincent JL, Russell JA, Silva E, Trzaskoma B, et al. Early changes in organ function predict eventual survival in severe sepsis. Crit Care Med. 2005;33(10):2194-201. https://doi.org/10.1097/01. ccm.0000182798.39709.84 PMid:16215369

25. Giuliano KK. Physiological monitoring for critically ill patients: Testing a predictive model for the early detection of sepsis. Am J Crit Care. 2007;16(2):122-30; quiz 131. https://doi.org/10.4037/ ajcc2007.16.2.122 PMid:17322011

26. Liu A, Bui T, Van Nguyen H, Ong B, Shen Q, Kamalasena D. Serum C-reactive protein as a biomarker for early detection of bacterial infection in the older patient. Age Ageing. 2010;39(5):559-65. https://doi.org/10.1093/ageing/afq067 PMid:20573779

27. Shapiro NI, Trzeciak S, Hollander JE, Birkhahn R, Otero R, Osborn TM, et al. A prospective, multicenter derivation of a biomarker panel to assess risk of organ dysfunction, shock, and death in emergency department patients with suspected sepsis. Crit Care Med. 2009;37(1):96-104. https://doi.org/10.1097/ ccm.0b013e318192fd9d PMid: 19050610

28. Wilson JX, Young GB. Sepsis-associated encephalopathy: Evolving concepts. Neurol J Southeast Asia 2003;8:65-76.

29. Lagu T, Rothberg MB, Shieh MS, Pekow PS, Steingrub JS, Lindenauer PK. What is the best method for estimating the burden of severe sepsis in the United States? J Crit Care. 2012;27(4):414.e1-9. https://doi.org/10.1186/cc14095 PMid:22516143

30. Melville J, Ranjan S, Morgan P. ICU mortality rates in patients with sepsis before and after the Surviving Sepsis Campaign. Crit
Care. 2015;19(Suppl 1):P15. https://doi.org/10.1186/cc14095

31. Ferreira FL, Bota DP, Bross A, Mélot C, Vincent JL. Serial evaluation of the SOFA score to predict outcome in critically ill patients. JAMA. 2001;286(14):1754-8. https://doi.org/10.1001/ jama.286.14.1754

PMid:11594901

32. Liu B, Chen YX, Yin Q, Zhao YZ. Diagnostic value and prognostic evaluation of Presepsin for sepsis in an emergency department. Crit Care. 2013;17(5):R244. https://doi.org/10.1186/cc13070 PMid:24138799

33. Yousef AA, Suliman GA. The predictive prognostic values of serum TNF-alpha in comparison to SOFA score monitoring in critically ill patients. Biomed Res Int 2013;2013:258029. https:// doi.org/10.1155/2013/258029

PMid:24175285

34. Daviaud F, Grimaldi D, Dechartres A, Charpentier J, Geri G, Marin N, et al. Timing and causes of death in septic shock. Ann Intensive Care. 2015;5(1):16.

PMid:26092499

35. Suhler E, Lin W, Yin HL, Lee WM. MD Decreased plasma gelsolin concentrations in acute liver failure, myocardial infarction, septic shock, and myonecrosis. Crit Care Med. 1997;25(4):594-8. https://doi.org/10.1097/00003246-199704000-00007 PMid:9142022

36. Lee PS, Waxman AB, Cotich KL, Chung SW, Perrella MA, Stossel TP. Plasma gelsolin is a marker and therapeutic agent in animal sepsis. Crit Care Med. 2007;35(3):849-55. https://doi. org/10.1097/01.ccm.0000253815.26311.24 PMid:17205019

37. Lee PS, Patel SR, Christiani DC, Bajwa E, Stossel TP, Waxman AB. Plasma gelsolin depletion and circulating actin in sepsis a pilot study. PLoS One. 2008;3(11):e3712. https://doi. org/10.1371/journal.pone.0003712

PMid: 19002257

38. Cohen TS, Bucki R, Byfield FJ, Ciccarelli NJ, Rosenberg B, DiNubile MJ, et al. Therapeutic potential of plasma gelsolin administration in a rat model of sepsis. Cytokine. 2011;54(3):235-8. https://doi.org/10.1016/j.cyto.2011.02.006 PMid:21420877

39. Wang H, Cheng B, Chen Q, Wu S, Lv C, Xie GH, et al. Time course of plasma gelsolin concentrations during severe sepsis in critically ill surgical patients. Crit Care. 2008;12(4):R106. https://doi.org/10.1186/cc6988

PMid:18706105

40. Huang LF, Yao YM, Li JF, Dong D, Liu C, Yu Y, et al. Reduction of plasma gelsolin levels correlates with development of multiple organ dysfunction syndrome and fatal outcome in burn patients. PLoS One. 2011;6(11):e25748. https://doi.org/10.1371/journal. pone. 0025748

41. Lee PS, Sampath K, Karumanchi SA, Tamez H, Bhan I, Isakova $\mathrm{T}$, et al. Plasma gelsolin and circulating actin correlate with hemodialysis mortality. J Am Soc Nephrol. 2009;20(5):11408. https://doi.org/10.1681/asn.2008091008 PMid:19389844। 